\title{
Idiopathic Inflammatory Myopathy
}

National Cancer Institute

\section{Source}

National Cancer Institute. Idiopathic Inflammatory Myopathy. NCI Thesaurus. Code

C116796.

An umbrella term for diseases which have chronic muscle inflammation and weakness of unknown etiology. The types of idiopathic inflammatory myopathy are further defined by either clinicopathologic criteria or by the presence of certain autoantibodies. 